\title{
Multicentre analysis of intensity of care at the end-of-life in patients with advanced cancer, combining health administrative data with hospital records: variations in practice call for routine quality evaluation
}

Isabelle Colombet ${ }^{1,2^{*}}$ (D), Carole Bouleuc ${ }^{3}$, Alain Piolot ${ }^{4}$, Aurélie Vilfaillot $^{5}$, Hélène Jaulmes $^{6}$, Sabine Voisin-Saltiel ${ }^{7}$, François Goldwasser ${ }^{8}$, Pascale Vinant ${ }^{1}$ and the EFIQUAVIE study group

\begin{abstract}
Background: Accessible indicators of aggressiveness of care at the end-of-life are useful to monitor implementation of early integrated palliative care practice. To determine the intensity of end-of-life care from exhaustive data combining administrative databases and hospital clinical records, to evaluate its variability across hospital facilities and associations with timely introduction of palliative care (PC).

Methods: For this study designed as a decedent series nested in multicentre cohort of advanced cancer patients, we selected 997 decedents from a cohort of patients hospitalised in 2009-2010, with a diagnosis of metastatic cancer in 3 academic medical centres and 2 comprehensive cancer centres in the Paris area. Hospital data was combined with nationwide mortality databases. Complete data were collected and checked from clinical records, including first referral to $P C$, chemotherapy within 14 days of death, $\geq 1$ intensive care unit (ICU) admission, $\geq 2$ emergency department visits (ED), and $\geq 2$ hospitalizations, all within 30 days of death.

Results: Overall (min-max) indicator values as reported by facility providing care rather than the place of death, were: $16 \%(8-25 \%)$ patients received chemotherapy within 14 days of death, $16 \%$ (6-32\%) had $\geq 2$ admissions to acute care, $6 \%(0-15 \%)$ had $\geq 2$ emergency visits and 18\% (4-35\%) had $\geq 1$ intensive care unit admission(s). Only 53\% of these patients met the $P C$ team, and the median (min-max) time between the first intervention of the PC team and death was 41 (17-112) days. The introduction of PC > 30 days before death was independently associated with lower intensity of care.
\end{abstract}

Conclusions: Aggressiveness of end-of-life cancer care is highly variable across centres. This validates the use of indicators to monitor integrated PC in oncology. Disseminating a quality audit-feedback cycle should contribute to a shared view of appropriate end-of-life care objectives, and foster action for improvement among care providers.

Keywords: (MesH heading or entry terms), End of life care, Quality of health care, Palliative care, Cancer care facilities, Academic medical centers, Data collection methods

\footnotetext{
* Correspondence: isabelle.colombet@parisdescartes.fr;

isabelle.colombet@aphp.fr

'Unité Fonctionnelle de Médecine Palliative, Hôpital Cochin, Assistance

Publique Hôpitaux de Paris, F-75014 Paris, France

${ }^{2}$ Univ Paris Descartes, F-75006 Paris, France

Full list of author information is available at the end of the article
}

(c) The Author(s). 2019 Open Access This article is distributed under the terms of the Creative Commons Attribution 4.0 International License (http://creativecommons.org/licenses/by/4.0/) which permits unrestricted use, distribution, and reproduction in any medium, provided you give appropriate credit to the original author(s) and the source, provide a link to the Creative Commons license, and indicate if changes were made. The Creative Commons Public Domain Dedication waiver (http://creativecommons.org/publicdomain/zero/1.0/) applies to the data made available in this article, unless otherwise stated. 


\section{Background}

Despite increased survival following advances in early detection and treatment, numbers of deaths from cancer are expected to increase as a result of the ageing population. Efforts to improve the quality of end-of-life cancer care are therefore important. One of the challenges for quality management is the efficient measurement of care quality with rapid feedback to healthcare organizations enabling them to undertake necessary actions for improvement. Earle et al. [1] developed indicators involving focus groups with patients, carers and health professionals, designed to be easily accessible and measurable from health administrative data and to provide meaningful information on the quality of end-of-life cancer care. These indicators describe high-intensity medical care delivered in the last month of life, such as overuse of chemotherapy, underuse of hospice care, frequent hospitalizations, emergency room visits, and intensive care unit admissions. They set some achievable benchmarks from the results of the $10 \%$ best-performing providers [2-4]. The methodology was also tested in Canada [5], and the indicators were endorsed by the American $\mathrm{Na}$ tional Quality Forum [3]. Since these original developments, and with the computerization of clinical activities and easier access to large health administrative databases, these indicators have been used in other countries [6-8], in child populations $[8,9]$, or for specific types of cancer $[10,11]$. In France, a study described the chemotherapy indicator, using nation-wide hospital administrative data, primarily collected for hospital payment without recording outpatient care [12]. In another study, all Earle's indicators were used to evaluate the effect of integrated palliative care on the quality of end-of-life care from exhaustive data in an academic medical centre [13].

Based on evidence from several randomized clinical trials, American Society of Clinical Oncology (ASCO) as well as European Society of Medical Society (ESMO) published guidelines to recommend patients and outpatients with advanced cancer should receive dedicated palliative care services, early in the course of disease, concurrent with active treatment $[14,15]$. A Cochrane meta-analysis confirmed that early palliative care could improve quality of life and reduce symptom intensity with no effect reaching statistical significance on survival [16]. Some studies found that early palliative care also had a favorable impact on end-of-life care aggressiveness, suggesting that such indicators as chemotherapy administration or intensive care resource use can be considered as interesting to monitor implementation of early palliative care practice [17-21].

In this multicentre study, we selected a cohort of patients diagnosed with metastatic cancer in 5 academic medical centres or comprehensive cancer centres. The study aimed to determine the intensity and trajectory of end-of-life cancer care from exhaustive data combining administrative databases and hospital clinical records, to evaluate their variability across hospital facilities and their association with timely integration of palliative care.

\section{Methods \\ Design and setting}

We conducted a retrospective analysis of a nested series of decedents in a cohort selected from the administrative data of 2 comprehensive cancer centres and 3 academic medical centres in the Paris region. All 2010 decedents were identified from these hospitals' administrative databases and by linkage with national death certificates database, to analyse quality indicators for all inpatients diagnosed with advanced cancer, whatever their place of death. Quality indicators were then measured from hospital administrative database, completed by data collected from health records. The REporting of studies Conducted using Observational Routinely collected health Data (RECORD) guidelines were followed when relevant to report methods and results [22].

Organisation of the hospital-based palliative care consultation team is similar in each centre. The team comprises at least a palliative care physician and a palliative care nurse who collaborate systematically with social workers and psychologists. They can be called on by attending physicians to evaluate in- or outpatients, give advice on symptom relief, and provide support for carers or healthcare professionals.

None of the participating centres has an inpatient palliative care unit.

\section{Data sources and study population}

Patients over 18 years of age were selected from each hospital administrative database (PMSI database, the French equivalent of DRG database), based on a hospital stay coded under metastatic cancer ICD-10 diagnosis (C76_, C78_, C79_, C80_), between October 1, 2009 and December 31, 2010. Patients recorded as deceased in 2010 the database of one of the facilities were identified. For patients whose death was not found in the hospital administrative database on the date of the request, a vital status search was performed on the National Vital Statistics (RNIPP, for National Register for the Identification of Private Individuals) database, by application to the national death certificate database to obtain the cause and place of death [23, 24]. All 2010 decedents in the initial cohort selected from hospital administrative databases were thus identified, whatever their place of death. Two hundred patients per centre were randomly selected from this decedent series, stratified according to age, gender and place of death (in hospital or elsewhere), 
to form a sample of 1000 patients, equally spread across the 5 participating centres and representative of each.

\section{Measures of intensity of care}

For the 200 patients selected in each centre, a second request to each hospital administrative database was made to enable the reconstruction of clinical trajectories in the last month of life: the number of visits to emergency room or oncology clinic, the number of admissions to intensive care unit or to acute care.

\section{Additional data collected from clinical records}

The data extracted from hospital administrative database was systematically checked and completed individually for each patient by a search of hospital clinical records in each participating centre. Additional data described the exact date of the first intervention of the palliative care team, and, when available, the modalities of last administered chemotherapy (route and exact date of prescribing). We also checked clinical records to appreciate whether the centre where the patient was identified was the patient's reference centre for cancer treatment, and the length of the patient's follow-up in that centre. The study protocol was approved by the CEERB $\left(\mathrm{N}^{\circ}\right.$ IRB00006477).

\section{Statistical analyses}

Quantitative and qualitative variables were described by means (SD) and frequencies (\%). For results per centre, each patient was reported in the centre where he/she was identified by request to the hospital administrative database. First, Chi-square and Student tests were performed to assess the associations between outcomes (i.e. measures of intensity of care) and the following covariates: age at death, gender, disease incurable at initial diagnosis, number of metastasis sites, study centre, intervention of palliative care team, group of primary tumor sites (defined in 3 categories of expected survival according to published French epidemiological data) at least one admission in an intensive care unit, at least one admission in acute care, at least one emergency visit. Then, logistic regressions were used to predict the logit of the probability of experiencing each outcome. Since the outcome indicators of quality of end of life care include the timeframe of the last 30 days of life (e.g. emergency visit, intensive care unit or acute care admission in the last 30 days of life), we represented the timely intervention of palliative care team variable as "Early intervention of palliative care team ( $>30$ days before death)" versus "No or late intervention of palliative care team $(<30$ days before death)". Variables with a $p$-value under 0.05 in the simple analysis were included in the multivariable analysis, making analysis of the effect of palliative care within the same timeframe of the last 30 days of life difficult. In addition, we conducted some sensitivity analysis only for the place of death outcome, in order to test the question of palliative care versus no palliative care (using other representation of "No intervention" versus "Intervention of palliative care"), separately from the question of early versus late palliative care.

All statistical tests were two sided and a $p$-value under 0.05 was considered statistically significant. All analyses were performed using SAS software version 9.4.

\section{Results}

Study population and patient characteristics per Centre

A total of 7858 patients were hospitalized with a diagnosis of metastatic cancer between October 2009 and December 2010 in the 5 participating centres, among whom 2063 were identified as decedents in 2010 (see Fig. 1); 724 (35\%) patients who died outside hospital were identified thanks to the request to RNIPP. From these 2063 patients, a random sample of 1000 patients was drawn to pursue data collection from clinical records. Three patients were excluded from the analysis due to identity or primary diagnosis errors.

Men accounted for $54 \%$, mean age $66( \pm 14.2)$ years at the time of death (Table 1). The most frequent primary tumor sites were breast (18\%), lung (17\%), urogenital (prostate, bladder, kidney, 14\%) and colon/rectum (11\%). In the study population, $599(66 \%)$ patients had $\geq 2$ metastatic sites, most frequently liver (48\%), bone (43\%), lung $(42 \%)$, peritoneal $(20 \%)$ and brain $(16 \%)$.

\section{Intensity of end-of-life care}

All indicators were highly variable across centres (Table 2).

Of the 738 patients for whom the data could be found in hospital records, $16 \%$ received chemotherapy in their last 14 days of life (Table 2). This proportion varied across centres, from 8.1 to $13.2 \%$ in the three academic medical centres and reached 16 and 25\% in Comprehensive Cancer Centres 1 and 2. The last line of chemotherapy was started at a median of 42 days preceding death. It was prescribed by oral route for 54/236 (23\%) patients.

Concerning clinical trajectories in the last month before death, in the overall study population, $16.4 \%$ were hospitalized twice or more (reaching 32\% for Comprehensive Cancer Centre 2) and 90\% of these admissions were motivated by needs for palliative or supportive care.

Sixty-one $(6 \%)$ patients visited emergency room twice or more. Only $10(3.4 \%)$ of these visits led to hospitalisation. In all $17.5 \%$ were admitted at least once to intensive care unit, with a median length of stay of 4 days. Between-centre variations for these indicators should be interpreted bearing in mind that Comprehensive Cancer Centre 1 has no emergency room, and is organized to receive patients in need of urgent care in unplanned 


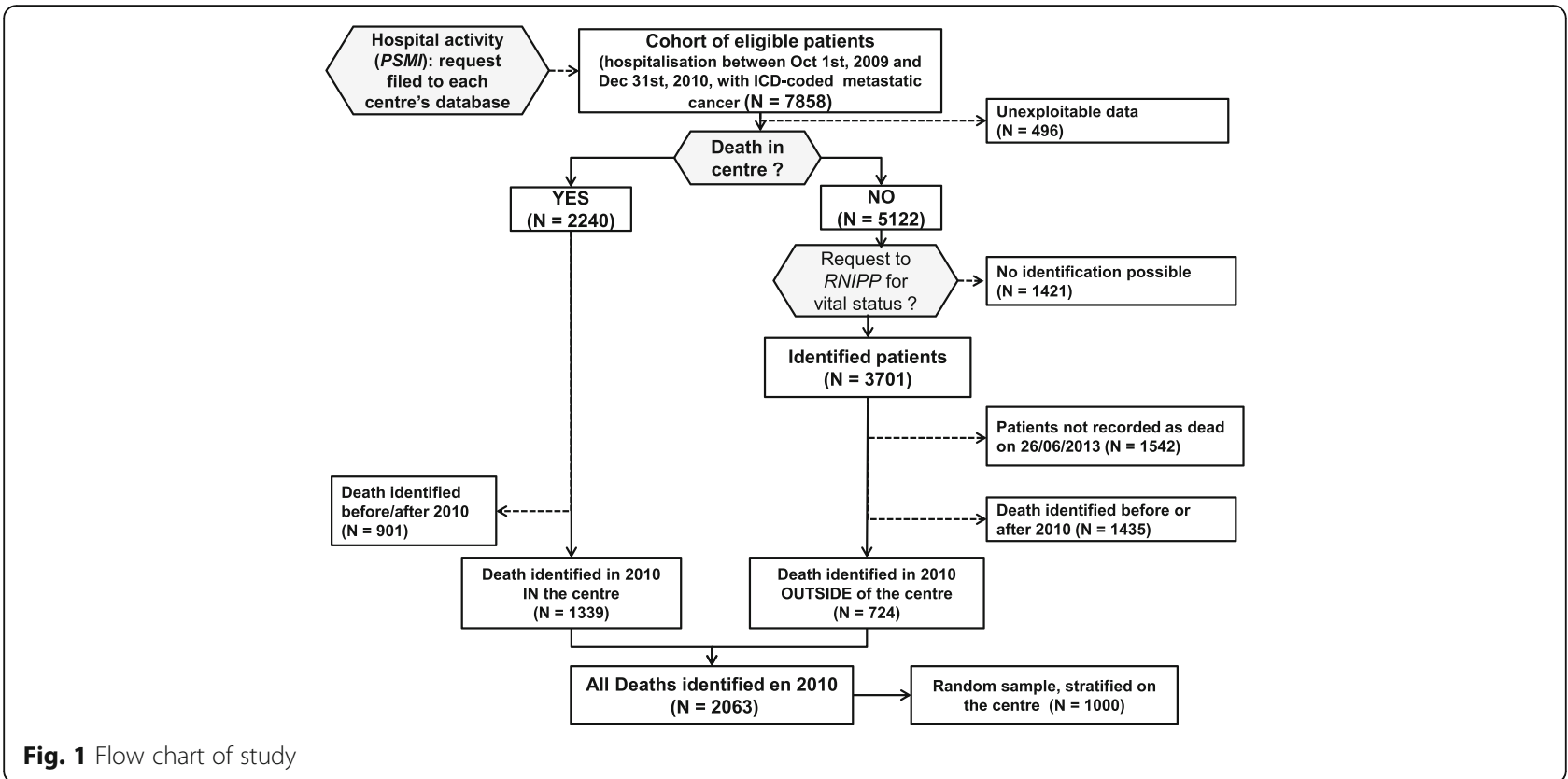

consultations, or addresses them to the emergency room in a nearby public hospital.

\section{Impact of palliative care on intensity of end-of-life care}

The median anteriority of follow up differed across centres and the timing of referral to palliative care should be read in this context (Table 3). Both comprehensive cancer centres were considered as the referent centre for more than $90 \%$ of the patients (respectively 93 and $98 \%$ ) and a large majority had been followed for over 6 months. In the overall population, the palliative care team was mobilized for 492 (53\%) patients, the proportion ranging from $30 \%$ in academic medical centre 2 to $70 \%$ in comprehensive cancer centre 1 .

Table 4 shows the results of the multivariable logistic regression analyses. The intervention of a palliative care team more than 30 days before death was associated with lower likelihood of receiving chemotherapy near death (OR 0.50 [IC95\% 0.30-0.82]), of being admitted to acute care in the last month (OR 0.64 [IC95\% 0.460.89 ]), and of dying in acute care unit (OR 0.33 [IC95\% 0.23-0.47]). According to sensitivity analyses for the place of death outcome, the intervention of palliative care team, whenever its timing, as compared with no intervention, was still significantly associated with more frequent dying in acute care unit (OR 0.40 [IC95\% 0.280.57], $p<0.0001$ ) .

No other covariable was significantly associated with intensity of care, except the centre and older age. The centre was significantly associated with all indicators, and older age only associated with less chemotherapy near death (OR 0.97 [IC95\% 0.96-0.98]).

Table 1 Patient characteristics by centre

\begin{tabular}{|c|c|c|c|c|c|c|}
\hline & $\begin{array}{l}\text { TOTAL } \\
n=997\end{array}$ & $\begin{array}{l}\text { UH } 1 \\
n=200\end{array}$ & $\begin{array}{l}\text { CCC 1 } \\
n=200\end{array}$ & $\begin{array}{l}\text { UH } 2 \\
n=199\end{array}$ & $\begin{array}{l}\text { CCC 2 } \\
n=200\end{array}$ & $\begin{array}{l}\text { UH } 3 \\
n=198 \\
\end{array}$ \\
\hline Age at death, mean (SD) & $66(14)$ & $68(13)$ & $64(14)$ & $70(13)$ & $60(14)$ & $70(13)$ \\
\hline Men, n (\%) & $535(54)$ & $130(65)$ & $42(21)$ & $126(63)$ & $111(56)$ & $126(64)$ \\
\hline Primary tumor site, n (\%) & $n=976$ & $n=198$ & $n=200$ & $n=197$ & $n=200$ & $n=181$ \\
\hline Breast & $173(18)$ & $12(6.1)$ & $106(53)$ & $15(7.6)$ & $24(12)$ & $16(8.8)$ \\
\hline Lung & $165(17)$ & $32(16)$ & $27(14)$ & $48(24)$ & $40(20)$ & $18(9.9)$ \\
\hline Urinary tract and kidney & $136(14)$ & $31(16)$ & $9(4.5)$ & $40(20)$ & $19(9.5)$ & $37(20)$ \\
\hline Colorectal & $104(11)$ & $21(11)$ & $9(4.5)$ & $24(12)$ & $23(12)$ & $27(15)$ \\
\hline Liver, Pancreas, Biliary tract & $89(9.1)$ & $31(16)$ & $4(2.0)$ & $15(7.6)$ & $10(5.0)$ & $29(16)$ \\
\hline Other & 309 (32) & 71 (36) & $45(23)$ & 55 (28) & $84(42)$ & $54(30)$ \\
\hline
\end{tabular}


Table 2 Intensity in end-of-life care, per centre

\begin{tabular}{|c|c|c|c|c|c|c|c|c|c|c|c|c|}
\hline & \multicolumn{2}{|l|}{ TOTAL } & \multicolumn{2}{|l|}{ UH 1} & \multicolumn{2}{|l|}{ CCC 1} & \multicolumn{2}{|l|}{$\mathrm{UH} 2$} & \multicolumn{2}{|l|}{$\operatorname{CCC} 2$} & \multicolumn{2}{|l|}{$\mathrm{UH} 3$} \\
\hline & n & (\%) & $\bar{n}$ & (\%) & n & (\%) & n & (\%) & n & (\%) & n & (\%) \\
\hline Chemotherapy in last 14 days of life & $116 / 738$ & $(15.7)$ & $15 / 126$ & $(11.9)$ & $30 / 185$ & $(16.2)$ & $21 / 159$ & $(13.2)$ & $42 / 169$ & $(24.9)$ & $8 / 99$ & (8.1) \\
\hline Trajectory of care in last month of life & \multicolumn{2}{|l|}{$n=997$} & \multicolumn{2}{|l|}{$n=200$} & \multicolumn{2}{|l|}{$n=200$} & \multicolumn{2}{|l|}{$n=199$} & \multicolumn{2}{|l|}{$n=199$} & \multicolumn{2}{|c|}{$n=198$} \\
\hline 1 admission in acute care & 520 & $(52.2)$ & 101 & $(50.5)$ & 92 & $(46.0)$ & 113 & $(56.8)$ & 103 & $(51.5)$ & 111 & $(56.1)$ \\
\hline$\geq 2$ admissions in acute care & 164 & $(16.4)$ & 27 & $(13.5)$ & 35 & $(17.5)$ & 27 & (13.6) & 64 & $(32.0)$ & 11 & (5.6) \\
\hline 1 emergency visit & 197 & (19.8) & 57 & (28.5) & 11 & $(5.5)$ & 60 & $(30.2)$ & 89 & $(44.5)$ & 41 & $(20.7)$ \\
\hline$\geq 2$ emergency visits & 61 & $(6.1)$ & 9 & $(4.5)$ & 0 & . & 13 & (6.5) & 29 & $(14.5)$ & 10 & $(5.1)$ \\
\hline$\geq 1$ admission in Intensive Care Unit & 174 & $(17.5)$ & 35 & $(17.5)$ & 8 & $(4.0)$ & 38 & $(19.1)$ & 23 & $(11.5)$ & 70 & $(35.4)$ \\
\hline Patients transferred in palliative care unit & \multicolumn{2}{|l|}{$n=157$} & \multicolumn{2}{|l|}{$n=33$} & \multicolumn{2}{|l|}{$n=58$} & \multicolumn{2}{|l|}{$n=29$} & \multicolumn{2}{|l|}{$n=10$} & \multicolumn{2}{|c|}{$n=19$} \\
\hline$\leq 3$ days before death & 12 & $(7.6)$ & 0 & - & 3 & (5.2) & 6 & (20.7) & 0 & - & 3 & (15.8) \\
\hline Place of Death & \multicolumn{2}{|l|}{$n=978$} & \multicolumn{2}{|l|}{$n=199$} & \multicolumn{2}{|l|}{$n=189$} & \multicolumn{2}{|l|}{$n=199$} & \multicolumn{2}{|l|}{$n=198$} & \multicolumn{2}{|c|}{$n=193$} \\
\hline Acute care hospital & 672 & $(68.7)$ & 129 & $(64.8)$ & 95 & (50.3) & 139 & $(69.8)$ & 182 & (91.9) & 127 & $(65.8)$ \\
\hline Acute care ward & 583 & $(59.6)$ & 113 & $(56.8)$ & 93 & $(49.2)$ & 115 & (57.8) & 146 & $(73.7)$ & 116 & $(60.1)$ \\
\hline Intensive Care Unit & 62 & (6.3) & 15 & $(7.5)$ & 2 & (1.1) & 22 & (11.1) & 17 & (8.6) & 6 & (3.1) \\
\hline Emergency room & 27 & $(2.8)$ & 1 & $(0.5)$ & 0 & . & 2 & $(1.0)$ & 19 & (9.6) & 5 & (2.6) \\
\hline Palliative care unit & 189 & $(19.3)$ & 41 & (20.6) & 60 & $(31.7)$ & 32 & $(16.1)$ & 10 & (5.1) & 46 & (23.8) \\
\hline Home & 82 & (8.4) & 24 & $(12.1)$ & 13 & (6.9) & 24 & (12.1) & 4 & (2.0) & 17 & (8.8) \\
\hline Other & 35 & (3.6) & 5 & $(2.5)$ & 21 & (11.1) & 4 & (2.0) & 2 & (1.0) & 3 & (1.6) \\
\hline
\end{tabular}

Abbreviations: CCC Comprehensive Cancer Centre, UH University Hospital

\section{Discussion}

This study provides exhaustive baseline data on the intensity and trajectory of end-of-life care delivered to adult populations with metastatic cancer in two comprehensive cancer centres and three academic hospitals in the Paris area. Its results highlight some inter-centre variability of practice, with $\mathrm{max} / \mathrm{min}$ ratios between 3 and 9, depending on indicators. Hardly more than half patients met the hospital-based palliative care consultation team. Adjusting for centre effect, the intervention of the palliative care team more than a month before death was significantly associated with lesser likelihood of patients receiving chemotherapy near death and greater likelihood of dying in palliative care unit or at home.

Results obtained from large nationwide health administrative data are interesting to give a broad view of practice. Studies of these indicators from other countries reveal large variations which can be explained by differences in healthcare systems and public health policies at the national level, and by heterogeneity in measurement methods and data sources [4, 6, 12, 25-27]. Our findings remain in the broad range of results published. It is necessary for a good performance measure to detect

Table 3 Clinical trajectory and context of referral to palliative care

\begin{tabular}{|c|c|c|c|c|c|c|}
\hline & TOTAL & UH 1 & CCC 1 & $\mathrm{UH} 2$ & $\operatorname{CcC} 2$ & $\mathrm{UH} 3$ \\
\hline $\begin{array}{l}\text { Study centre is referent for the patient's } \\
\text { cancer, n/total (\%) }\end{array}$ & 842/932 (90) & $181 / 200(91)$ & 196/200 (98) & 163/199 (82) & 187/200 (94) & 115/133 (87) \\
\hline $\begin{array}{l}\text { Anteriority of follow up in the centre, } \\
\text { Median time in months (Q1 - Q3) }\end{array}$ & $12(4-37)$ & $10(4-24)$ & $33(9-106)$ & $8(3-21)$ & $17(6-43)$ & $8(2-21)$ \\
\hline Intervention by the Palliative Care Team, n/total (\%) & 492/926 (53) & 101/196 (52) & 140/199 (70) & 59/196 (30) & 112/199 (56) & $81 / 136(60)$ \\
\hline ECOG PS at 1 st intervention $\leq 2$ & $95 / 349(27)$ & 23/67 (34) & $43 / 83(52)$ & $5 / 21(24)$ & 12/101 (12) & $12 / 77(16)$ \\
\hline Time between first intervention and date of death & $n=475$ & $n=98$ & $n=138$ & $n=55$ & $n=107$ & $n=77$ \\
\hline$\leq 7$ days & $81(17)$ & $12(12)$ & $10(2,7)$ & $10(18)$ & $32(30)$ & $17(22)$ \\
\hline ]7-30] days & $117(25)$ & $15(15)$ & $19(14)$ & $22(40)$ & $35(33)$ & $26(34)$ \\
\hline ]30-90] days & $128(27)$ & $39(40)$ & $31(23)$ & $14(26)$ & $24(22)$ & $20(26)$ \\
\hline$>90$ days & 149 (31) & $32(33)$ & $78(57)$ & $9(16)$ & $16(15)$ & $14(18)$ \\
\hline median (Q1 - Q3) & $41(13-122)$ & $63(25-115)$ & $112(38-281)$ & $25(11-50)$ & $17(7-54)$ & $21(8-64)$ \\
\hline
\end{tabular}


Table 4 Unadjusted frequencies of each indicator by delivery of palliative care and multivariable logistic regression predicting intensity of care near death

\begin{tabular}{|c|c|c|c|c|c|c|c|}
\hline \multirow[b]{2}{*}{ Indicators } & \multicolumn{2}{|c|}{$\begin{array}{l}\text { Early intervention of } \mathrm{PCT} \\
\text { (> } 30 \text { days before death) }\end{array}$} & \multicolumn{2}{|c|}{$\begin{array}{l}\text { No or late intervention of PCT } \\
\text { (<30 days before death) }\end{array}$} & \multicolumn{3}{|c|}{ Multivariable analysis $^{a}$} \\
\hline & $\mathrm{n}$ & (\%) & $\mathrm{n}$ & (\%) & OR & IC95\% & $p$-value \\
\hline Chemotherapy in last 14 days of life & $28 / 240$ & $(11.7)$ & $89 / 487$ & $(18.3)$ & 0.50 & {$[0.30-0.82]$} & 0.006 \\
\hline$\geq 1$ emergency visits & $62 / 282$ & $(22.0)$ & $188 / 644$ & $(29.2)$ & 1.04 & {$[0.72-1.49]$} & 0.844 \\
\hline$\geq 1$ admission in ICU & $49 / 282$ & $(17.4)$ & $114 / 644$ & $(17.7)$ & 1.45 & {$[0.95-2.21]$} & 0.082 \\
\hline$\geq 1$ admission in acute care & $180 / 282$ & $(63.8)$ & $481 / 644$ & $(74.7)$ & 0.64 & {$[0.46-0.89]$} & 0.009 \\
\hline Place of death in acute care hospital & $153 / 273$ & $(56.0)$ & $511 / 637$ & $(80.2)$ & $0.33^{\mathrm{b}}$ & {$[0.23-0.47]$} & $<0.0001$ \\
\hline
\end{tabular}

Abbreviations: PCT Palliative Care Team, ICU Intensive Care Unit

${ }^{a}$ Odds Ratio of indicator, according to the timing of intervention of PCT, adjusted on age at death, gender, disease incurable at initial diagnosis, number of metastasis sites, group of primary tumor sites (defined in 3 categories of expected survival according to published French epidemiological data), and study centre balso adjusted on previous indicators of intensity of care

differences in quality of care. We obtained a significant variability of practice between the 5 participating centres, similar to the results of Earle et al. whose ratios between the 5\% best and 5\% worst performing health care geographic areas ranged from 2.2 to 5 , according to outcome [2].

We found high frequencies of chemotherapy administration in the 14 days before death, with overuse more frequent in comprehensive cancer centres than in academic medical centres and higher intensity of care among young patients, as previously reported in the French national hospital administrative database [12].

Another strength of this study is the collection of data from clinical records giving access to the accurate timing of the first intervention of the palliative care team which is not recorded in hospital administrative database [28]. This allowed to describe large variations in the timing of referral to palliative care teams across centres and to analyse the accurate association between this intervention and the indicators of intensity of care. These variations suggest that early palliative care, known to improve quality-of-life [16] and internationally recommended for patients with advanced cancer [14, 15], is unequally put into practice. More systematic monitoring of the median time between first referral to palliative care and death as an indicator of this practice could provide interesting leverage for change [29, 30].

However, the study cohort was recruited from academic medical centres and comprehensive cancer centres only, making overall results on indicators not representative of all patients with advanced cancer. As one centre (comprehensive cancer centre 1) is specialized in breast cancer treatment, and another (academic medical centre 1) is an expert centre for the diagnosis and treatment of sarcoma, women and young patients were over-represented. We found a particularly high rate of patients admitted at least once in intensive care unit during their last month (18\%) and the proportion of deaths at home observed in our study is lower than that reported nationally for cancer deaths (8\% versus 19\%) [31]. In their European study from death certificates, Cohen et al. give some insights into between-country variations concerning place of death and quality indicator results. French healthcare organization is characterized by a high proportion of people dying in hospital, especially from cancer $(>70 \%)$, alongside one of the highest ratios per 10,000 of both acute care hospital beds and long term care beds. Among the other 8 European countries participating in the study, France also has the highest healthcare and social welfare expenditure, with the lowest rates of palliative care services for adults per million inhabitants.

\section{Conclusion}

This study brings a first multicentre measure of all Earle's indicators in French setting, from health administrative data completed by hospital clinical records. It supports a prospective approach to quality of care, reporting indicators of practice from the point of view of cancer care providers, by facility providing care rather than the place of death. Unlike results obtained from large health administrative databases which bring a macroscopic view of practice at the national level, our approach provide practitioners with the opportunity to reflect on their practice knowing their own specificities and organization, and to engage in a quality evaluation-improvement cycle at each centre level [32]. Our results also add to those other practice evaluation studies which found that early palliative care could have a favourable impact on end-of-life care aggressiveness $[20,21]$. This suggests that routine measure of such indicators as chemotherapy administration, acute care resource use in the last month of life and timing of first referral to specialized palliative care should be recommended to monitor actual implementation of early palliative care practice and end-of-life care quality at health care facility level. 


\section{Acknowledgements}

We also thank all other collaborators of the EFIQUAVIE study group: Dr. Jérôme Alexandre (oncologist, for Cochin centre), Dr. Muriel Mons (IGR), Dr. François Hemery (Hôp H Mondor), Dr. Samir Bouam (Hôp Cochin), Ilhem Cherrak (HEGP), Pr Gilles Chatellier (HEGP), as collaborators facilitating access to administrative databases in each centre and providing data management counseling.

We also thank Dr. Pierre Durieux for his critical review and advice on manuscript.

\section{Funding}

The EFIQUAVIE study was funded by the French Ministry of Health ("Programme Hospitalier de Recherche Clinique", from the Direction Générale de I'Offre de Soins; PHRC 2010, grant number AOM 10 249). The funding source had no role in the design and conduct of the study; collection, management, analysis, and interpretation of the data; preparation, review, or approval of the manuscript; and the decision to submit the manuscript for publication.

\section{Availability of data and materials}

Dataset can be made available for review process, upon request to Dr. I Colombet (corresponding author) or to Aurélie Vilfaillot (aurelie.vilfaillot@aphp.fr).

\section{Authors' contributions}

IC made substantial contributions to the conception AND design of the work AND the acquisition, analysis AND interpretation of data AND drafted the work and substantively revised it. CB and PV made substantial contributions to the conception AND design of the work AND interpretation of data AND drafted the work and substantively revised it. AP, HJ, SV-S made substantial contributions to the acquisition AND interpretation of data. AV made substantial contributions to the analysis AND interpretation of data AND drafted the work and substantively revised it. FG made substantial contributions to the conception AND interpretation of data. AND ALL authors have read and approved approved the submitted version AND have agreed both to be personally accountable for their own contributions and to ensure that questions related to the accuracy or integrity of any part of the work, even ones in which the author was not personally involved, are appropriately investigated, resolved, and the resolution documented in the literature.

\section{Ethics approval and consent to participate}

The study analyses a retrospective series of human decedents and is not considered by French law as an interventional research involving human subjects. However, the use of health administrative database planned for decedent's identification and data collection, was not yet clearly regulated by French Law at the time of the protocol elaboration. Therefore, the study protocol has been submitted to the Institutional Review Board ( $N^{\circ}$ IRB00006477) of Paris North Hospitals, Paris 7 University, AP-HP (Comité d'Evaluation de l'Ethique des projets de Recherche Biomédicale (CEERB) du GHU Nord) for advice and methods validation and it has been approved.

\section{Consent for publication}

Not applicable

\section{Competing interests}

The authors declare that they have no competing interests.

\section{Publisher's Note}

Springer Nature remains neutral with regard to jurisdictional claims in published maps and institutional affiliations.

\section{Author details}

'Unité Fonctionnelle de Médecine Palliative, Hôpital Cochin, Assistance Publique Hôpitaux de Paris, F-75014 Paris, France. ${ }^{2}$ Univ Paris Descartes, F-75006 Paris, France. ${ }^{3}$ Département de Soins de Support, Institut Curie, Paris, France. ${ }^{4}$ Unité Mobile d'Accompagnement et de Soins Palliatifs, Hôpital Henri Mondor, Assistance Publique Hôpitaux de Paris, F-94000 Créteil, France. ${ }^{5}$ Unité de Recherche Clinique, Hôpital européen G Pompidou, Hôpitaux Universitaire Paris Ouest, Assistance Publique Hôpitaux de Paris, F-75015 Paris, France. ${ }^{6}$ Unité Mobile d'Accompagnement et de Soins Palliatifs, Hôpital européen G Pompidou, Hôpitaux Universitaire Paris Ouest, Assistance Publique Hôpitaux de Paris, F-75015 Paris, France. ${ }^{7}$ Unité Mobile d'Accompagnement et de Soins Palliatifs, Institut Gustave Roussy, Villejuif,
France. ${ }^{8}$ Oncologie, Hôpital Cochin, Hôpitaux Universitaire Paris Centre, Assistance Publique Hôpitaux de Paris, F-75014 Paris, France.

Received: 5 January 2019 Accepted: 27 March 2019

Published online: 05 April 2019

\section{References}

1. Earle CC. Identifying potential indicators of the quality of end-of-life Cancer care from administrative data. J Clin Oncol. 2003;21(6):1133-8.

2. Earle CC. Evaluating claims-based indicators of the intensity of end-of-life cancer care. Int J Qual Health Care. 2005;17(6):505-9.

3. Earle CC, Landrum MB, Souza JM, Neville BA, Weeks JC, Ayanian JZ. Aggressiveness of Cancer care near the end of life: is it a quality-of-care issue? J Clin Oncol. 2008;26(23):3860-6.

4. Setoguchi S, Earle CC, Glynn R, Stedman M, Polinski JM, Corcoran CP, et al. Comparison of prospective and retrospective indicators of the quality of end-of-life Cancer care. J Clin Oncol. 2008;26(35):5671-8.

5. Grunfeld E, Lethbridge L, Dewar R, Lawson B, Paszat LF, Johnston G, et al. Towards using administrative databases to measure population-based indicators of quality of end-of-life care: testing the methodology. Palliat Med. 2006;20(8):769-77.

6. Ho TH, Barbera L, Saskin R, Lu H, Neville BA, Earle CC. Trends in the aggressiveness of end-of-life Cancer Care in the Universal Health Care System of Ontario, Canada. J Clin Oncol. 2011;29(12):1587-91.

7. Hung Y-N, Liu T-W, Lin D-T, Chen Y-C, Chen J-S, Tang ST. Receipt of lifesustaining treatments for Taiwanese pediatric patients who died of Cancer in 2001 to 2010: a retrospective cohort study. Medicine (Baltimore). 2016; 95(16):e3461.

8. Park JD, Kang HJ, Kim YA, Jo M, Lee ES, Shin HY, et al. Trends in the aggressiveness of end-of-life care for Korean pediatric cancer patients who died in 2007-2010. PLoS One. 2014;9(6):e99888.

9. Kassam A, Sutradhar R, Widger K, Rapoport A, Pole JD, Nelson K, et al. Predictors of and trends in high-intensity end-of-life care among children with Cancer: a population-based study using health services data. J Clin Oncol Off J Am Soc Clin Oncol. 2017;35(2):236-42.

10. Jang RW, Krzyzanowska MK, Zimmermann C, Taback N, Alibhai SMH. Palliative care and the aggressiveness of end-of-life care in patients with advanced pancreatic cancer. J Natl Cancer Inst. 2015;107(3):dju424. Available from: https://doi.org/10.1093/jnci/dju424.

11. Kao Y-H, Chiang J-K. Effect of hospice care on quality indicators of end-oflife care among patients with liver cancer: a national longitudinal population-based study in Taiwan 2000-2011. BMC Palliat Care. 2015;14(1) Available from: http://bmcpalliatcare.biomedcentral.com/articles/10.1186/ s12904-015-0036-9. [cited 2018 Jun 18].

12. Rochigneux P, Raoul JL, Beaussant Y, Aubry R, Goldwasser F, Tournigand C, et al. Use of chemotherapy near the end of life: what factors matter? Ann Oncol Off J Eur Soc Med Oncol. 2017;28(4):809-17.

13. Colombet I, Montheil V, Durand J-P, Gillaizeau F, Niarra R, Jaeger C, et al. Effect of integrated palliative care on the quality of end-of-life care: retrospective analysis of 521 cancer patients. BMJ Support Palliat Care. 2012; 2(3):239-47.

14. Ferrell BR, Temel JS, Temin S, Alesi ER, Balboni TA, Basch EM, et al. Integration of palliative care into standard oncology care: American Society of Clinical Oncology clinical practice guideline update. J Clin Oncol. 2017; 35(1):96-112.

15. Kaasa S, Loge JH, Aapro M, Albreht T, Anderson R, Bruera E, et al. Integration of oncology and palliative care: a lancet oncology commission. Lancet Oncol. 2018. Available at https://doi.org/10.1016/s1470-2045(18)30415-7.

16. Haun MW, Estel S, Rücker G, Friederich $\mathrm{H}-\mathrm{C}$, Villalobos $\mathrm{M}$, Thomas $\mathrm{M}$, et al. Early palliative care for adults with advanced cancer. Cochrane Database Syst Rev. 2017;6:CD011129.

17. Temel JS, Greer JA, Muzikansky A, Gallagher ER, Admane S, Jackson VA, et al. Early palliative care for patients with metastatic non-small-cell lung cancer. N Engl J Med. 2010;363(8):733-42.

18. Maltoni M, Scarpi E, Dall'Agata M, Schiavon S, Biasini C, Codecà C, et al. Systematic versus on-demand early palliative care: a randomised clinical trial assessing quality of care and treatment aggressiveness near the end of life. Eur J Cancer. 2016;69:110-8.

19. Temel JS, Greer JA, El-Jawahri A, Pirl WF, Park ER, Jackson VA, et al. Effects of early integrated palliative Care in Patients with Lung and GI Cancer: a randomized clinical trial. J Clin Oncol. 2017;35(8):834-41. 
20. Triplett DP, LeBrett WG, Bryant AK, Bruggeman AR, Matsuno RK, Hwang L, et al. Effect of palliative care on aggressiveness of end-of-life care among patients with advanced Cancer. J Oncol Pract. 2017;13(9):e760-9.

21. Scibetta C, Kerr K, Mcquire J, Rabow MW. The costs of waiting: implications of the timing of palliative care consultation among a cohort of decedents at a Comprehensive Cancer Center. J Palliat Med. 2016;19(1):69-75.

22. Benchimol El, Smeeth L, Guttmann A, Harron K, Moher D, Petersen I, et al. The REporting of studies conducted using observational routinely-collected health data (RECORD) statement. PLoS Med. 2015;12(10):e1001885.

23. PROCEDURE_ACCES_RNIPP_UTILISATEURS_V2_19_05_2014.pdf. Available from: http://cesp.vif.inserm.fr/ webifr/pdf/PROCEDURE_ACCES_RNIPP UTILISATEURS_V2_19_05_2014.pdf. [cited 2018 Jun 18]

24. CépiDc - causes médicales de décès. Available from: http://www.cepidc. inserm.fr/index.php? $\mathrm{p}=$ accueil. [cited 2018 Jun 18]

25. Keam B, Oh D-Y, Lee S-H, Kim D-W, Kim MR, Im S-A, et al. Aggressiveness of Cancer-care near the end-of-life in Korea. Jpn J Clin Oncol. 2008;38(5):381-6.

26. Yun YH, Kwak M, Park SM, Kim S, Choi JS, Lim H-Y, et al. Chemotherapy use and associated factors among Cancer patients near the end of life. Oncology. 2007;72(3-4):164-71

27. Bekelman JE, Halpern SD, Blankart CR, Bynum JP, Cohen J, Fowler R, et al. Comparison of site of death, health care utilization, and hospital expenditures for patients dying with Cancer in 7 developed countries JAMA. 2016;315(3):272-83.

28. Goldwasser F, Vinant P, Aubry R, Rochigneux P, Beaussant $Y$, Huillard $O$, et al. Timing of palliative care needs reporting and aggressiveness of care near the end of life in metastatic lung cancer: a national registry-based study. Cancer. 2018;124(14):3044-51.

29. Vinant P, Joffin I, Serresse L, Grabar S, Jaulmes H, Daoud M, et al. Integration and activity of hospital-based palliative care consultation teams: the INSIGHT multicentric cohort study. BMC Palliat Care. 2017;16(1):36.

30. Colombet I, Vinant P, Joffin I, Weiler F, Chaillot N, Moreau N, et al. Suivi d'indicateurs dans le bilan d'activité d'une équipe mobile de soins palliatifs : un levier pour l'amélioration des pratiques. Presse Med. 2015:44:e1-11.

31. Cohen J, Pivodic L, Miccinesi G, Onwuteaka-Philipsen BD, Naylor WA, Wilson DM, et al. International study of the place of death of people with cancer: a population-level comparison of 14 countries across 4 continents using death certificate data. Br J Cancer. 2015;113(9):1397-404.

32. Cowall DE, Yu BW, Heineken SL, Lewis EN, Chaudhry V, Daugherty JM. Endof-life Care at a Community Cancer Center. J Oncol Pract. 2012:8(4):e40-4.

Ready to submit your research? Choose BMC and benefit from:

- fast, convenient online submission

- thorough peer review by experienced researchers in your field

- rapid publication on acceptance

- support for research data, including large and complex data types

- gold Open Access which fosters wider collaboration and increased citations

- maximum visibility for your research: over $100 \mathrm{M}$ website views per year

At BMC, research is always in progress.

Learn more biomedcentral.com/submissions 